\title{
Enantioselective $\alpha$-Amination of 1,3-Dicarbonyl Compounds in Batch and Flow with Immobilized Thiourea Organocatalysts
}

\author{
Pinar Kasaplar, ${ }^{\mathrm{a}}$ Erhan Ozkal, ${ }^{\mathrm{a}}$ Carles Rodríguez-Escrich ${ }^{\mathrm{a}}$ and Miquel A. Pericàs ${ }^{\mathrm{a}, \mathrm{b} *}$
}

A polymer-supported bifunctional thiourea organocatalyst (PS-TU) has been prepared and successfully used in the enantioselective $\alpha$-amination of 1,3-dicarbonyl compounds with azodicarboxylates. In contrast with homogeneous thioureas, PS-TU is not irreversibly deactivated by the azodicarboxylate reagents, and simple washing with triethylamine between runs has allowed the repeated reuse ( 9 cycles) of the PS-TU catalyst. The $\alpha$-amination mediated by PS-TU has also been adapted to perform the enantioselective amination (93\% ee) of ethyl 2-oxocyclopentanecarboxylate in continuous flow ( $7.5 \mathrm{~h}$ operation, 21 min residence time, $\mathrm{TON}=37)$.

\section{Introduction}

The high cost usually associated to the preparation of chiral ligands and catalysts has prompted several research groups to embark in the study of immobilized analogues of these species. ${ }^{1}$ Ideally, properly designed solid-supported catalysts should retain the activity of their homogeneous counterparts while allowing for repeated recycling. In addition to this economic dimension, catalyst immobilization leads to important improvements in the sustainability characteristics of chemical processes; thus, the opportunity of separating and recovering the immobilized catalyst by simple filtration avoids in many instances the work-up stage, where most of the waste associated to chemical processes is generated. ${ }^{2}$ In the most favorable cases, immobilized catalysts should also allow the implementation of enantioselective continuous flow processes. ${ }^{3}$ After expansive growth of their use in the first decade of the 21 st century, ${ }^{4}$ organocatalysts have also proven to be most suitable candidates for immobilization on solid supports, ${ }^{5}$ as they avoid issues associated to metal leaching such as catalyst deactivation and product contamination. To this end, several inorganic $^{6}$ and organic bulk materials have been used as supports. Among the latter, polystyrene-derived resins ${ }^{7}$ have arguably been the most successful ones. Consequently, several polystyrene-supported chiral organocatalysts have been applied to the continuous flow preparation of enantioenriched compounds. ${ }^{8}$

One important requirement of immobilized catalysts in view of the development of processes with increased sustainability is chemical stability under operation conditions. If no deactivation occurs (i.e., if the catalyst TOF remains constant), high TON can be achieved with a given catalyst sample through repeated recycling (batch operation) or through long-lasting continuous operation (flow processing). ${ }^{9}$

In the field of aminocatalysis, it is known that enamine intermediates suffer irreversible degradation leading to deactivation of the parent organocatalysts through a variety of processes. ${ }^{10}$ The pathways allowing this deactivation are completely prevented when organocatalysts activating substrates through $\mathrm{H}$-bonding are used, since no covalent bonding is established between these catalysts and the reactant molecules. ${ }^{11}$ Moreover, aggregation-prone species like thioureas or squaramides usually present solubility issues that become irrelevant upon heterogenization onto swellable resins. For these reasons, the immobilization of H-bonding organocatalysts looking for improved chemical stability is a subject of current interest. Within this effort, we have recently developed the polystyrene-bound squaramide PS-SQ (1) (Figure 1a), which was successfully applied in Michael additions to nitroalkenes in batch ${ }^{12 \mathrm{a}}$ and flow. ${ }^{12 \mathrm{~b}}$ Shortly after, other authors reported alternative approaches to immobilize squaramide-type catalysts on polystyrene and silica. ${ }^{13}$ To expand the toolkit of supported H-bonding organocatalysts with the inclusion of another important privileged structures, we decided to prepare immobilized thiourea catalysts (Fig 1b). We wish to report in this paper the results of an iterative catalyst design leading to structurally simple, modular immobilized thioureas able to promote the enantioselective $\alpha$-amination of 1,3-dicarbonyl compounds with dialkyl azodicarboxylates in batch and flow. 
a) Previous work: ${ }^{12}$ supported squaramide<smiles>O=C(OCc1ccc(-c2cn(Cc3ccccc3)nn2)cc1)c1ccc(Nc2c(N[C@@H]3CCCCC3N3CCCCC3)c(=O)c2=O)cc1C(F)(F)F</smiles>

b) This work: supported thiourea

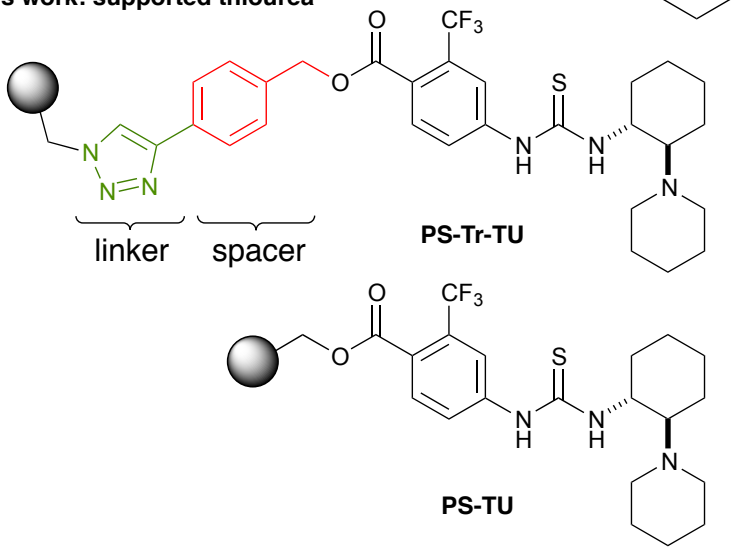

Figure 1. Polymer-supported squaramide and thiourea catalysts

\section{Results and discussion}

The organocatalytic $\alpha$-amination of carbonyl compounds with azodicarboxylates ( $\alpha$-hydrazination) was independently introduced in 2002 by Jorgensen ${ }^{14 \mathrm{a}}$ and List, ${ }^{14 \mathrm{~b}}$ using proline as a catalyst. In spite of the interest of the reaction, that could allow the catalytic asymmetric synthesis of natural and unnatural amino acids from cheap starting materials, the process has received comparatively little attention due to problems of catalyst deactivation. Indeed, it is known that secondary amines attack the highly electrophilic azodicarboxylate reagents leading to inactive triazanes. ${ }^{15}$ As discussed above, H-bonding organocatalysts could in principle avoid this problem. However, an initial attempt by Takemoto with the archetypal thiourea organocatalyst in the $\alpha$ hydrazination of cyclic 1,3-dicarbonyl compounds was not successful. ${ }^{16}$ This failure was attributed to catalyst deactivation by reaction of the nucleophilic sulphur centre on the thiourea with the electrophilic azodicarboxylate species. ${ }^{17}$ This difficulty could be circumvented either by replacing the thiourea catalyst by a usually less efficient urea analogue ${ }^{16}$ or, later on, by employing thioureas at inconveniently low temperatures. ${ }^{18}$ To the best of our knowledge, despite the precedents where homogeneous organocatalysts are used for the $\alpha$-hydrazination of 1,3-dicarbonyl compounds, ${ }^{19}$ no examples of this reaction involving reusable catalysts have been described. We reasoned that a polystyrene-supported thiourea would exhibit a less nucleophilic character due to the presence in the close vicinity of the bulky polymer backbone, so that a catalyst with these characteristics could perform the selective $\alpha$-hydrazination without being deactivated by the azodicarboxylate reagent.

Polystyrene-supported thiourea PS-Tr-TU (Figure 1b), prepared with the same immobilization strategy than squaramide PS-SQ, was our initial catalyst candidate. This material could be prepared in a straightforward manner as shown in Scheme 1.

The known amino ester $1^{12 a}$ was immobilized onto $1 \%$ DVB azidomethyl polystyrene $\left(f=0.52 \mathrm{mmol} \mathrm{g}^{-1}\right)$ in quantitative yield by means of a copper-catalyzed alkyne-azide cycloaddition (CuAAC) reaction ${ }^{20}$ mediated by the TTM $\cdot \mathrm{CuCl}$ complex, ${ }^{21}$ which is compatible with primary amines. The amino-functionalized resin 2 was then easily converted to the catalytic resin PS-Tr-TU through a two-step sequence involving formation of the isothiocyanate resin $\mathbf{3}$ and reaction with readily available enantiopure $(1 R, 2 R)$-2-(piperidin-1yl)cyclohexanamine (4). The catalytic resin was obtained with a functionalization of $0.38 \mathrm{mmol} \mathrm{g}^{-1}$, corresponding to an overall functionalization yield of $93 \%$.<smiles>C#Cc1ccc(COC(=O)c2ccc(N)cc2C(F)(F)F)cc1</smiles> 
However, inconsistent results were recorded in catalysis with this species, and we reasoned that this behaviour could find its origin in the triazole linker, due to the uncontrolled presence in the catalytic resin of copper traces from the CuAAC reaction. To test this hypothesis, we decided to avoid the triazole linker for the immobilization of the thiourea.

Thus, we set our sights on supported thiourea PS-TU (see Figure 1) where the triazole linker and the associated $p$ phenylene spacer have been suppressed. The preparation of this highly simplified catalytic resin (Scheme 2) took place through immobilization of the Fmoc-protected amino acid 6 onto a $1 \%$ DVB Merrifield resin $\left(f=0.53 \mathrm{mmol} \mathrm{g}^{-1}\right)$ followed by deprotection to afford the PS-supported amino ester 7. This intermediate was then converted to the target catalytic resin PSTU through a two-step sequence involving formation of the isothiocyanate resin $\mathbf{8}$ and reaction with readily available, enantiopure $(1 R, 2 R)$-2-(piperidin-1-yl)cyclohexanamine (4). The catalytic resin was obtained with a functionalization of $0.43 \mathrm{mmol} \mathrm{g}^{-1}$, corresponding to an overall functionalization yield of $97 \%$. Very gratifyingly, all batches of PS-TU catalyst prepared by this method gave reproducible results in the $\alpha$ amination of 1,3-dicarbonyls with azodicarboxylates, as opposed to the poorly reliable PS-Tr-TU. It is interesting to note that isothiocyanate resins $\mathbf{3}$ and $\mathbf{8}$ are highly versatile intermediates since they can be reacted with a variety of primary/tertiary diamines to provide libraries of PS-supported bifunctional thioureas.
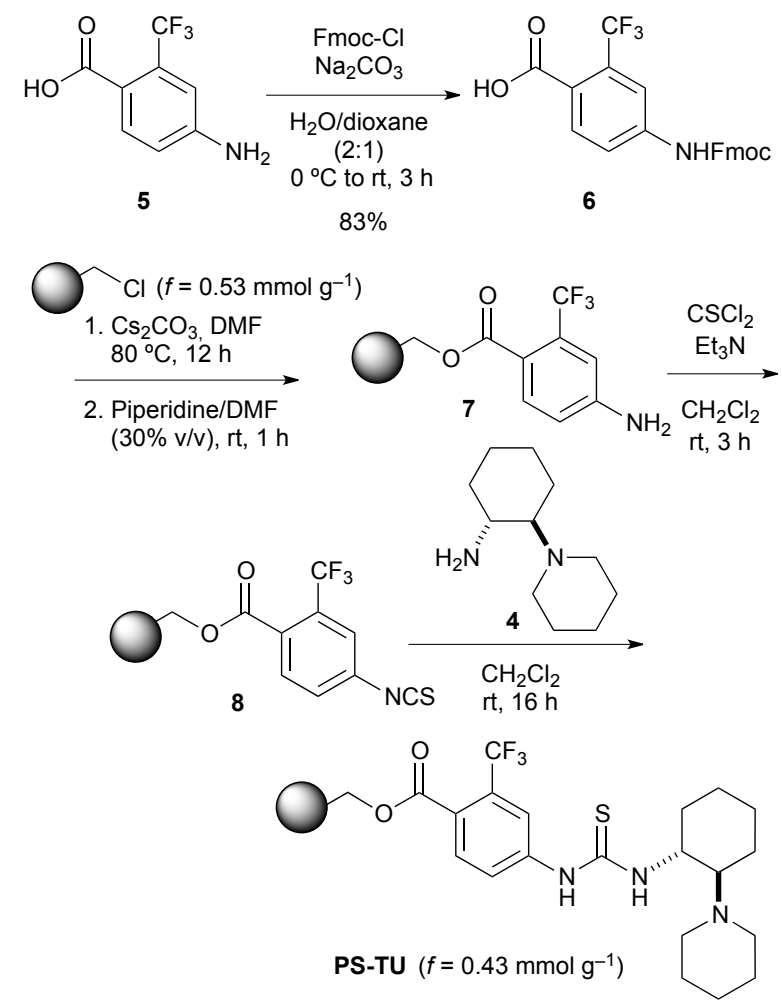

Scheme 2. Synthesis of the triazole-free PS-thiourea catalyst (PS-TU).
When the PS-TU catalyst was tested in the addition of ethyl 2oxocyclopentanecarboxylate (9a) to di-tert-butyl azodicarboxylate (10a) (Table 1, entry 1), we were pleased to find that with only $5 \mathrm{~mol} \%$ of the bifunctional catalyst the $\alpha$ amination product 11a was obtained in very high yield in $4 \mathrm{~h}$ at room temperature. The high enantioselectivity achieved (94\% ee) is remarkable in two senses: first, it confirms the suitability of the immobilized thiourea catalyst for the $\alpha$-amination reaction and the validity of its simplified design. Second, compared to closely related homogeneous catalysts, ${ }^{16,18}$ our supported thiourea gives good ee's even at room temperature. Moreover, and in sharp contrast with previously reported immobilized squaramides suitable for work in flow, ${ }^{12}$ the use of dichloromethane as a solvent was not necessary to achieve high catalytic activities and ee's. Instead, toluene could be used, rendering the process more benign.

Table 1. Substrate scope in the $\alpha$-amination of cyclic 1,3-dicarbonyl compounds with the immobilized H-bonding catalyst PS-TU.

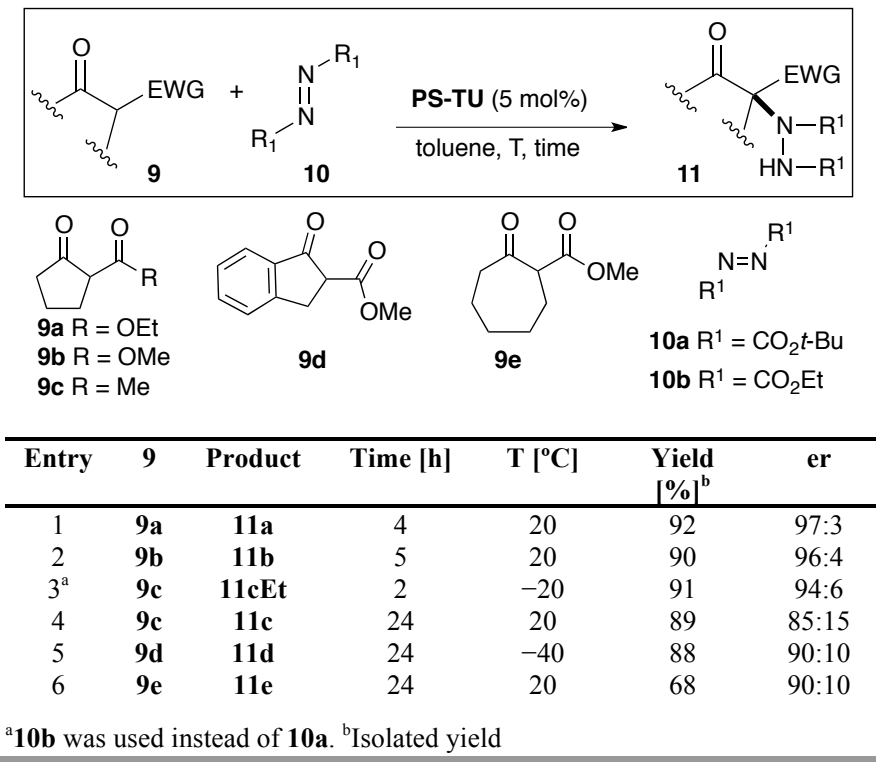

The reaction was next tested with a family of cyclic 1,3dicarbonyl compounds. Despite the fact that polystyrene resins swell poorly below $0{ }^{\circ} \mathrm{C}$, some substrates were tested at low temperature in an attempt to improve the enantioselectivity of the reaction. As shown in Table 1, substrates bearing a fivemembered ring and an ester functionality (Table 1, entries 1-2) give very high yields and enantioselectivities. For fivemembered rings with an exocyclic ketone, reactions with 10a were completed in $24 \mathrm{~h}$ with moderate enantioselectivity. On the other hand, when diethyl azodicarboxylate (10b) was employed, even when cooling down at $-20{ }^{\circ} \mathrm{C}$ full conversion was observed in $2 \mathrm{~h}$ with good selectivity (entries 3-4). This was, however, the only case where the use of $\mathbf{1 0 b}$ instead of 10a had a big impact on the reaction. Indanone derivative 9d (entry 5) furnished the product at room temperature or at $0{ }^{\circ} \mathrm{C}$ 
in very short time, albeit with low ee. Rather unexpectedly, further cooling to $-40{ }^{\circ} \mathrm{C}$ did not deactivate the catalytic resin, good results being obtained at such unusually low temperature (entry 5). While $\beta$-ketoester 9e involving a seven-membered ring was an adequate substrate for the reaction, affording the $\alpha$ hydrazination product with good selectivity at room temperature (entry 6), the analogous six-membered ring derivative $9 \mathrm{f}$ failed to react in a variety of conditions. Finally, when an acyclic substrate such as cyanoacetate 9 g (Figure 2) was tested in the reaction, a fast reaction took place but with enantioselectivity much lower $(20 \%$ ee) than that recorded with a related homogeneous thiourea catalyst. ${ }^{22}$<smiles>COC(=O)C1CCCCC1=O</smiles>

9f<smiles>CCOC(=O)C(C#N)c1ccccc1</smiles>

9g
Figure 2. Challenging substrates.

Next, experiments of catalyst recycling were performed for the reaction between 9a and 10a. Disappointingly, initial recycling attempts showed a fast decrease in catalytic activity (see ESI). Although this could result from the nucleophilic deactivation of thioureas by azodicarboxylates already noted by Takemoto in homogeneous phase, ${ }^{17}$ we considered that this interaction would be severely hindered by the neighbouring polymer backbone. As an alternative explanation, ${ }^{23}$ we attributed this decay to protonation of the basic tertiary amine moiety. To our delight, we found that simply washing the resin with triethylamine between cycles sufficed to regenerate the catalytic activity. In this way, very high conversions (>95\%), high isolated yields and ee's were consistently recorded over 9 cycles with the same catalyst sample (Table 2).

Table 2. Recycling experiments in the $\alpha$-amination of 9a with PS-TU under optimized conditions. ${ }^{a}$

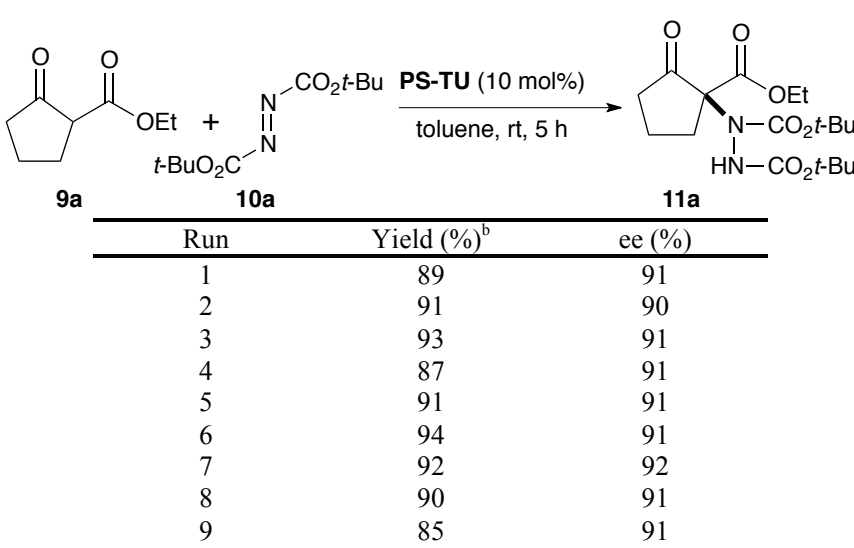

a After each run, the resin was shaken with $\mathrm{Et}_{3} \mathrm{~N}$ (1 equiv) in $\mathrm{CH}_{2} \mathrm{Cl}_{2}(1 \mathrm{~mL})$ for $30 \mathrm{~min}$ and washed with $\mathrm{CH}_{2} \mathrm{Cl}_{2}(3 \times 2 \mathrm{~mL})$. ${ }^{\text {b Isolated yield }}$
After securing the recyclability of PS-TU, we set our sights in the continuous process. The flow reactor consisted of a lowpressure chromatography column packed with PS-TU and fitted with two adjustable end-pieces (see ESI for further details). A pump was used to feed this "organocatalytic reactor" with a mixture of both reagents (chemically compatible in the absence of catalyst). A second pump was used to circulate a solution of $\mathrm{Et}_{3} \mathrm{~N}$ for catalyst reactivation. A preliminary test run with a solution of $9 \mathbf{a}, \mathbf{1 0 a}$ and $5 \mathrm{~mol} \%$ of $\mathrm{Et}_{3} \mathrm{~N}$ showed good initial performance, but the catalytic activity decreased after $2 \mathrm{~h}$. Taking into account the results obtained in the recycling experiments, we decided to implement a similar reactivation protocol in flow. Gratifyingly, the catalytic activity of the resin could be preserved over prolonged periods of time by periodically washing it with $\mathrm{Et}_{3} \mathrm{~N}$. This was carried out in a systematic manner by pumping the base for $20 \mathrm{~min}$ at $200 \mu \mathrm{L}$ $\min ^{-1}$ every $2 \mathrm{~h}$ of operation.

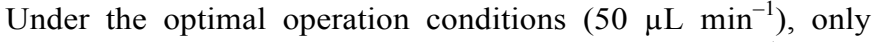
$0.128 \mathrm{mmol}$ of PS-TU ( $300 \mathrm{mg} ; f=0.426 \mathrm{mmol} \mathrm{g}^{-1}$ ) were sufficient to provide good results using a single feed channel containing 9a and 10a $(0.30 \mathrm{M}$ and $0.45 \mathrm{M}$, respectively) in toluene. To our delight, both conversion and ee remained high throughout the process (after $7.5 \mathrm{~h}$ : $88 \%$ conversion, $91 \%$ ee). Overall, this experiment led to the desired product (93\% ee) in $71 \%$ isolated yield $(1.81 \mathrm{~g}, 4.68 \mathrm{mmol})$ with a productivity of $4.88 \mathrm{mmol} \mathrm{mmol}_{\mathrm{cat}^{-1}} \mathrm{~h}^{-1}$ and a TON of 37 (Table 3), the residence time being $21 \mathrm{~min}$.

\section{Table 3. Continuous flow $\alpha$-amination with PS-TU}

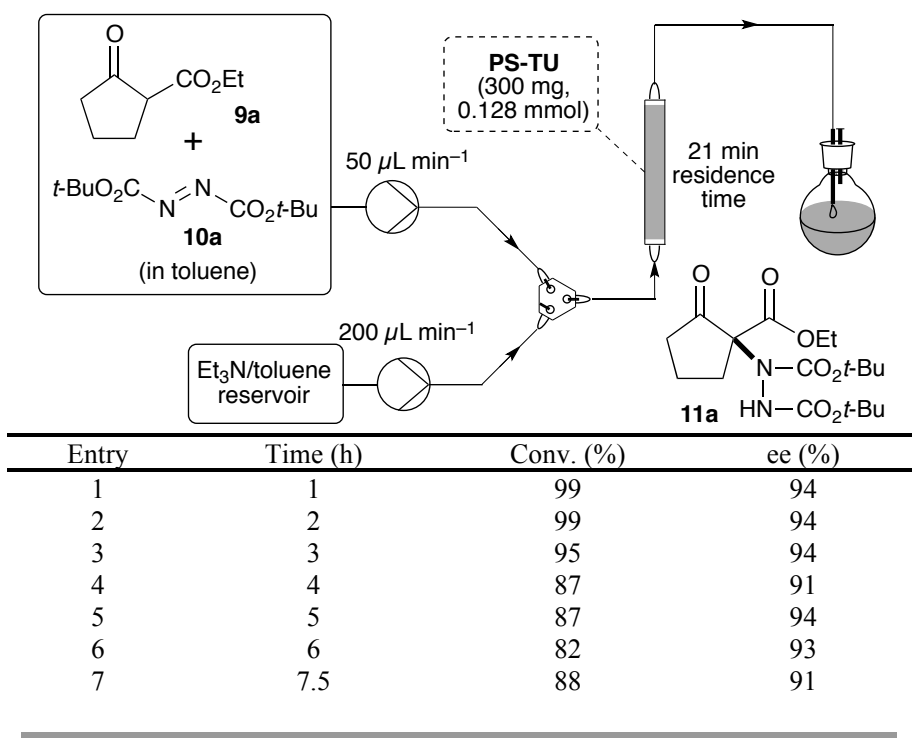

\section{Conclusions}

In summary, the synthesis of a modular, polymer-supported bifunctional thiourea has been performed through a highly simplified approach avoiding the use of linkers/spacers. This catalyst has shown very high activity and enantioselectivity in the $\alpha$-amination of 1,3-dicarbonyl compounds at room 
temperature, approaching the performance of homogeneous thioureas. Interestingly, these reactions represent one of the rare examples of highly enantioselective creation of quaternary centers using immobilized catalytic species. ${ }^{24}$ A strategy involving mild basic washings between runs has allowed repeated recycling of this catalytic resin. Remarkably, PS-TU is one of the first examples of a chiral thiourea organocatalyst that can be successfully reused for extended periods of time. ${ }^{25,26} \mathrm{~A}$ similar approach to prevent deactivation has allowed the implementation of the first continuous flow process based on a solid-supported thiourea. Overall, this represents an interesting alternative to the previously reported immobilized squaramides and, given the versatility of thiourea catalysts and the modularity of our approach, it is expected to find application in many other processes.

\section{Experimental}

\section{Synthesis of the PS-TU resin}

\section{4-((((9H-FLUOREN-9-YL)METHOXY)CARBONYL)AMINO)-2- (TRIFLUOROMETHYL)BENZOIC ACID (6)}

Fluorenylmethyloxycarbonyl (Fmoc) chloride (566 mg, 2.18 mmol, 1 equiv. $)$ in dioxane $(10 \mathrm{~mL})$ was added dropwise to a solution of 4-amino-2-(trifluoromethyl)benzoic acid 5 (449 mg, $2.18 \mathrm{mmol}, 1$ equiv.) and sat. $\mathrm{Na}_{2} \mathrm{CO}_{3}$ (aq.) $(20 \mathrm{~mL})$ at $0-5{ }^{\circ} \mathrm{C}$. After stirring at $0-5{ }^{\circ} \mathrm{C}$ for $15 \mathrm{~min}$ and then at room temperature for 3 hours, water $(150 \mathrm{~mL})$ was added and the mixture was washed with diethyl ether $(100 \mathrm{~mL})$. The aqueous layer was acidified with $6 \mathrm{M}$ aqueous hydrochloric acid to $\mathrm{pH}=3$, the resulting white precipitate was filtered, washed with ice cold water and then vacuum dried overnight at $40{ }^{\circ} \mathrm{C}$ to afford product as a white solid (773 $\mathrm{mg}, 1.81 \mathrm{mmol}, 83 \%)$. mp: 202$203{ }^{\circ} \mathrm{C} .{ }^{1} \mathrm{H}$ NMR $\left(500 \mathrm{MHz}, \mathrm{DMSO}-d_{6}\right) \delta 10.28(\mathrm{~s}, 1 \mathrm{H}), 7.99$ (s, 1H), $7.91(\mathrm{~d}, J=7.5 \mathrm{~Hz}, 2 \mathrm{H}), 7.83(\mathrm{~d}, J=8.5 \mathrm{~Hz}, 1 \mathrm{H}), 7.81$ $-7.73(\mathrm{~m}, 3 \mathrm{H}), 7.43(\mathrm{t}, J=7.4 \mathrm{~Hz}, 2 \mathrm{H}), 7.39-7.33(\mathrm{~m}, 2 \mathrm{H})$, $4.56(\mathrm{~d}, J=6.5 \mathrm{~Hz}, 2 \mathrm{H}), 4.34(\mathrm{t}, J=6.4 \mathrm{~Hz}, 1 \mathrm{H}) .{ }^{13} \mathrm{C} \mathrm{NMR}$ $(126 \mathrm{MHz}, \mathrm{DMSO}) \delta 166.8,153.3,143.6(\times 2), 141.9,140.8$ $(\times 2), 131.9,128.1(\mathrm{q}, J=31.8 \mathrm{~Hz}), 127.7(\times 2), 127.1(\times 2)$, $125.0(\times 2), 124.9$ (br s), $125.5(\mathrm{q}, J=273.0 \mathrm{~Hz}), 120.5,120.2$ $(\times 2), 115.6(\mathrm{q}, J=5.8), 66.0,46.5$. IR (ATR): $v=3438,2995$, $1741,1710,1610,1518,1407,1291,1205,1154,1035 \mathrm{~cm}^{-1}$. HRMS (ESI-TOF): $m / z$ calcd. for $\mathrm{C}_{23} \mathrm{H}_{15} \mathrm{~F}_{3} \mathrm{NO}_{4} \quad[\mathrm{M}-\mathrm{H}]^{-}$: 426.0959, found 426.0971 .

\section{Polystyrene-SUPPORTED 4-AMinO-2-(TRIFlUOROMEThyl) BENZOATE (7)}

a) PS-NHFmoc: $1 \%$ DVB Merrifield resin $(1.00 \mathrm{~g}, 0.53 \mathrm{mmol}$, 1 equiv.) was swollen in dimethylformamide $(10 \mathrm{~mL})$ for 30 min. Then, caesium carbonate ( $1.00 \mathrm{~g}, 3.07 \mathrm{mmol}, 5.79$ equiv.) and the acid 6 ( $1.31 \mathrm{~g}, 3.07 \mathrm{mmol}, 5.79$ equiv.) were added to this mixture at $\mathrm{rt}$. The heterogeneous mixture was shaken at $\mathrm{rt}$ for $1 \mathrm{~h}$ and then at $80{ }^{\circ} \mathrm{C}$. After $12 \mathrm{~h}$, the resin was filtered and washed with acetone $(200 \mathrm{~mL})$, methanol $(200 \mathrm{~mL})$, water $(200$ $\mathrm{mL})$, acetone $(200 \mathrm{~mL})$ and THF $(300 \mathrm{~mL})$. Finally, the white resin was vacuum dried for $30 \mathrm{~min}$ and used directly in the next step. IR (ATR): $v=3387,3025,2924,1730,1625,1601,1492$, $1450,1286,1068 \mathrm{~cm}^{-1}$. Elemental analysis: $(\%)=\mathrm{N} 0.82, \mathrm{C}$ 87.13, $\mathrm{H}$ 7.14; $f=0.585 \mathrm{mmol} \cdot \mathrm{g}^{-1}$.

b) PS-NH $\mathbf{N H}_{2}$ (7): PS-NHFmoc ( $1.0 \mathrm{~g}, 0.53 \mathrm{mmol}, 1$ equiv.) was swollen for $30 \mathrm{~min}$ in dimethylformamide $(7 \mathrm{~mL})$ and piperidine $(3 \mathrm{~mL})$ was added dropwise to this mixture. The resulting heterogeneous light yellow mixture was shaken at rt. After $1 \mathrm{~h}$, it was filtered and the resin was washed with dimethylformamide $(60 \mathrm{~mL})$, THF $(60 \mathrm{~mL})$ and dichloromethane $(60 \mathrm{~mL})$. Finally, the white resin was vacuum dried for $30 \mathrm{~min}$ and used directly in the next step. IR (ATR): v $=3384,3059,2924,1728,1625,1601,1492,1451,1287,1068$ $\mathrm{cm}^{-1}$. Elemental analysis: $(\%)=\mathrm{N} 0.80, \mathrm{C} 86.41, \mathrm{H} 7.09 ; f=$ $0.571 \mathrm{mmol} \mathrm{g}^{-1}$.

\section{POLYSTYRENE-SUPPORTED 4-ISOTHIOCYANATO-2-(TRIFLUO- ROMETHYL) BENZOATE (8)}

$\mathrm{PS}^{-\mathrm{NH}_{2}}$ (7) (1.0 g, $0.50 \mathrm{mmol}, 1$ equiv.) was swollen for 30 min in dichloromethane $(10 \mathrm{~mL})$ and triethylamine $(0.278 \mathrm{~mL}$, $2.0 \mathrm{mmol}, 4.0$ equiv.) and thiophosgene ( $45 \mu \mathrm{L}, 0.60 \mathrm{mmol}, 1.2$ equiv.) were added dropwise to this suspension at rt. After $3 \mathrm{~h}$, the dark brown reaction mixture was filtered and the resin was washed with dichloromethane $(30 \mathrm{~mL})$, THF $(30 \mathrm{~mL})$, dichloromethane $(30 \mathrm{~mL})$, THF $(30 \mathrm{~mL})$, dichloromethane $(30$ $\mathrm{mL}$ ), and finally, the dark brown resin was vacuum dried for 30 min and used directly in the next step. IR (ATR): $v=3059$, 2922, 2023 (br), 1737, 1601, 1492, 1450, 1315, $1149 \mathrm{~cm}^{-1}$. Elemental analysis: $(\%)=\mathrm{N} 0.85, \mathrm{C} 85.14, \mathrm{H} 7.09, \mathrm{~S} 1.46 ; f=$ $0.606 \mathrm{mmol} \mathrm{g}^{-1}$.

\section{PS-TU CATALYST}

PS-isothiocyanate 8 (1.0 g, $0.50 \mathrm{mmol}, 1$ equiv.) was swollen for $30 \mathrm{~min}$ in dichloromethane $(5 \mathrm{~mL})$ and $(1 R, 2 R)-2-$ (piperidin-1-yl)cyclohexanamine $4(137 \mathrm{mg}, 0.75 \mathrm{mmol}, 1.5$ equiv.) in dichloromethane $(5 \mathrm{~mL})$ was added dropwise to this suspension at rt. After shaking for $16 \mathrm{~h}$, the dark brown reaction mixture was filtered and the resin was washed with dichloromethane $(30 \mathrm{~mL})$, THF $(30 \mathrm{~mL})$, dichloromethane (30 $\mathrm{mL})$, THF $(30 \mathrm{~mL})$, dichloromethane $(30 \mathrm{~mL})$, and finally, the dark brown resin was dried under vacuum at $35^{\circ} \mathrm{C}$ for $12 \mathrm{~h}$. IR (ATR): $v=3059,2924,1734,1601,1492,1450,1320,1164$, $1065 \mathrm{~cm}^{-1}$. Elemental analysis: $(\%)=\mathrm{N} 1.79, \mathrm{C} 83.84, \mathrm{H} 7.43$, $\mathrm{S} 1.26 ; f=0.426 \mathrm{mmol} \mathrm{g}^{-1}$.

\section{General procedure for the $\alpha$-amination reaction}

To a solution of PS-supported catalyst ( $5 \mathrm{~mol} \%$ ) in toluene $(0.5$ $\mathrm{mL})$ were added the corresponding azodicarboxylate $(0.2$ $\mathrm{mmol}$ ) and 1,3-dicarbonyl compound ( $0.3 \mathrm{mmol}, 1.5$ equiv.). The mixture was stirred at the reported temperature for each different substrate until TLC analysis showed that the limiting reagent was completely consumed. The catalyst was separated by filtration and washed with toluene $(2 \times 0.5 \mathrm{~mL})$. The combined organic phase was concentrated under vacuum, and the residue (excess 1,3-dicarbonyl compound plus $\alpha$-amination product) was directly purified by short path flash chromatography (silicagel; hexanes/ethyl acetate). After eluting 
the unreacted 1,3-dicarbonyl compound, polarity was increased to collect the pure $\alpha$-amination products $\mathbf{1 1}$.

(S)-Di-tert-butyl 1-(1-(ethoxycarbonyl)-2oxocyclopentyl)hydrazine-1,2-dicarboxylate (11a). ${ }^{27,28}$ Prepared in $92 \%$ yield and $94 \%$ ee $(71 \mathrm{mg}, 0.18 \mathrm{mmol})$. HPLC:

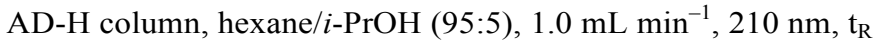
minor $=10.6 \mathrm{~min}, \mathrm{t}_{\mathrm{R}}$ major $=18.7 \mathrm{~min}$.

(S)-Di-tert-butyl 1-(1-(methoxycarbonyl)-2oxocyclopentyl)hydrazine-1,2-dicarboxylate (11b). ${ }^{27,29}$ Prepared in $90 \%$ yield and $92 \%$ ee $(67 \mathrm{mg}, 0.18 \mathrm{mmol})$. HPLC:

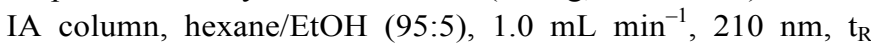
minor $=7.1 \mathrm{~min}, \mathrm{t}_{\mathrm{R}}$ major $=7.7 \mathrm{~min}$.

(R)-Diethyl 1-(1-acetyl-2-oxocyclopentyl)hydrazine-1,2dicarboxylate (11cEt). ${ }^{27,29}$

Prepared in $91 \%$ yield and $87 \%$ ee $(55 \mathrm{mg}, 0.18 \mathrm{mmol})$. HPLC:

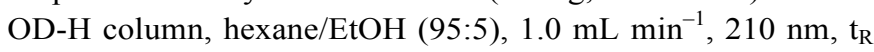
major $=11.6 \mathrm{~min}, \mathrm{t}_{\mathrm{R}}$ minor $=12.7 \mathrm{~min}$.

(R)-Di-tert-butyl 1-(1-acetyl-2-oxocyclopentyl)hydrazine-1,2dicarboxylate (11c). ${ }^{27,28}$

Prepared in $89 \%$ yield and $70 \%$ ee $(65 \mathrm{mg}, 0.18 \mathrm{mmol})$. HPLC: AD-H column, hexane/ $i$-PrOH (90:10), $1.0 \mathrm{~mL} \mathrm{~min}^{-1}, 210 \mathrm{~nm}$, $\mathrm{t}_{\mathrm{R}}$ minor $=5.9 \mathrm{~min}, \mathrm{t}_{\mathrm{R}}$ major $=7.5 \mathrm{~min}$.

(S)-Di-tert-butyl 1-(2-(methoxycarbonyl)-1-oxo-2,3-dihydro$1 \mathrm{H}$-inden-2-yl)hydrazine-1,2-dicarboxylate (11d). ${ }^{27,29}$

Prepared in $88 \%$ yield and $80 \%$ ee $(74 \mathrm{mg}, 0.18 \mathrm{mmol})$. HPLC:

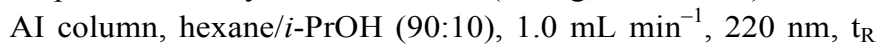
$\operatorname{minor}=11.4 \mathrm{~min}, \mathrm{t}_{\mathrm{R}}$ major $=15.4 \mathrm{~min}$.

(S)-Di-tert-butyl 1-(1-(methoxycarbonyl)-2oxocycloheptyl)hydrazine-1,2-dicarboxylate (11e). ${ }^{27,29}$ Prepared in $68 \%$ yield and $80 \%$ ee $(54 \mathrm{mg}, 0.14 \mathrm{mmol})$. HPLC:

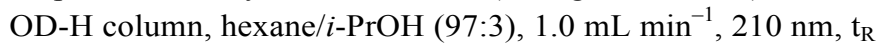
major $=6.4 \mathrm{~min}, \mathrm{t}_{\mathrm{R}}$ minor $=8.5 \mathrm{~min}$.

\section{General procedure for the recycling experiments in batch conditions}

To a solution of PS-TU (47 mg, $10 \mathrm{~mol} \%, f=0.426 \mathrm{mmol} \mathrm{g}^{-1}$ ) in toluene $(0.5 \mathrm{~mL})$ was added di-tert-butyl azodicarboxylate (46 mg, 0.2 mmol, 1 equiv.) and ethyl 2oxocyclopentanecarboxylate $(44 \mu \mathrm{L}, 0.3 \mathrm{mmol}, \mathrm{d}=1.054 \mathrm{~g}$ $\mathrm{mL}^{-1}, 1.5$ equiv.) and the suspension was shaken at rt. After 5 $\mathrm{h}$, the reaction mixture was filtered, and washed with dichloromethane $(15 \mathrm{~mL})$. The filtrate was concentrated under reduced pressure and purified by short path column chromatography on silica gel to afford the desired product. Before the following run, triethylamine $(50 \mu \mathrm{L})$ in dichloromethane $(1 \mathrm{~mL})$ was added to the recovered PS-catalyst in dichloromethane $(1 \mathrm{~mL})$ and the mixture was shaken at $\mathrm{rt}$. After $1 \mathrm{~h}$, the solution was filtered and the resin was washed with dichloromethane $(3 \times 5 \mathrm{~mL})$ and dried under vacuum at room temperature for $30 \mathrm{~min}$ to be directly used in the next reaction.

\section{Experimental set-up for the continuous flow amination catalyzed by PS-TU}

For the continuous flow experiments, the instrumental setup schematized in Table 4 was used. The packed bed reactor consisted of a vertically mounted and fritted low-pressure, glass chromatography column $(10 \mathrm{~mm}$ bore size and up to maximal $70 \mathrm{~mm}$ of adjustable bed height) loaded with the polymersupported thiourea resin PS-TU (300 $\mathrm{mg}, f=0.426 \mathrm{mmol} \mathrm{g}^{-1}$ ). The reactor inlet was connected to a three-way connector that allowed switching between two channels, connected to two different pumps. At the beginning, toluene was flushed for 30 $\min$ at $200 \mu \mathrm{L} \mathrm{min}{ }^{-1}$ flow rate to swell the resin. After that, this first channel was fed with a solution of di-tert-butyl azodicarboxylate (1.52 g, $6.59 \mathrm{mmol}, 1$ equiv.) and ethyl 2oxocyclopentanecarboxylate ( $1.46 \mathrm{~mL}, 9.89 \mathrm{mmol}, 1.50$ equiv.) in toluene $(22 \mathrm{~mL}$ ) (no reaction occurs in the absence of catalyst), which was pumped through the reactor at $50 \mu \mathrm{L} \mathrm{min}$ flow rate. The reactor outlet was connected to a receiving flask, where the product was collected. The second channel was connected to a flask containing triethylamine $(700 \mu \mathrm{L})$ in toluene $(25 \mathrm{~mL})$ to clean the system (every $2 \mathrm{~h}$, this solution was pumped through the reactor for $20 \mathrm{~min}$ at $200 \mu \mathrm{L} \mathrm{min}{ }^{-1}$ flow rate to restore catalytic activity and discarded without being collected). The formed product at any moment was characterized by ${ }^{1} \mathrm{H}$ NMR (conversion) and HPLC (enantiomeric excess) measurements of periodically collected samples. After $7.5 \mathrm{~h}$ of flowing the reactants, the flow process was stopped and the catalytic resin was washed with toluene for $30 \mathrm{~min}$. Then, the solvent was removed under reduced pressure and the crude was purified by flash column chromatography on silica gel (cyclohexane-ethyl acetate, 95:5 to 90:10) to afford the final product as a thick colourless oil with $71 \%$ isolated yield (1.81 g, $4.68 \mathrm{mmol})$.

Productivity: $4.88 \mathrm{mmol} \mathrm{mmol}_{\mathrm{cat}^{-1}} \mathrm{~h}^{-1}$; TON: 37 (over pure isolated product).

\section{Supporting Information}

General information, description of the experimental set-up for the continuous flow process, IR and NMR spectra, HPLC traces, and synthesis of the first generation immobilized thiourea (PS-Tr-TU).

\section{Acknowledgments}

This work was funded by MINECO (Grant CTQ2012-38594C02-01, Severo Ochoa Excellence Accreditation 2014-2018 (SEV-2013-0319) and FPI fellowship to P. K.), DEC Generalitat de Catalunya (Grant 2014SGR827 and BP-B fellowship to C. R.-E) and the ICIQ Foundation. E. O. is grateful for an ICIQ post-doctoral fellowship.

\section{Notes and references}


${ }^{a}$ Institute of Chemical Research of Catalonia (ICIQ).

Av. Països Catalans 16, 43007 Tarragona (Spain)

E-mail: mapericas@iciq.es

${ }^{b}$ Departament de Química Orgànica

Universitat de Barcelona, 08080 Barcelona (Spain).

Electronic Supplementary Information (ESI) available: General information, description of the experimental set-up for the continuous flow process, IR and NMR spectra, HPLC traces, and synthesis of the first generation immobilized thiourea (PS-Tr-TU). See DOI: $10.1039 / \mathrm{b} 000000 \mathrm{x} /$

1 (a) D. V. De Vos, I. F. J. Vankelecom, P. A. Jacobs, Chiral Catalyst Immobilization and Recycling. WILEY-VCH Verlag $\mathrm{GmbH} \mathbf{2 0 0 7}$; (b) K. Ding, Y. Uozumi, Handbook of Asymmetric Heterogeneous Catalysis Wiley-VCH Verlag GmbH 2008.

2 (a) Recoverable and Recyclable Catalysts (Ed. M. Benaglia), Wiley, Chichester, 2009; (b) Heterogenized Homogeneous Catalysts for Fine Chemicals Production (Eds. P. Barbaro and F. Liguori), Springer, Heidelberg, 2010.

3 (a) G. Jas, A. Kirschning, A. Chem. Eur. J. 2003, 9, 5708; (b) A. Kirschning, G. Jas, Applications of Immobilized Catalysts in Continuous Flow Processes in Immobilized Catalysts (Ed.: A. Kirschning), Springer, Berlin, 2004, Vol. 242, pp 209; (c) X. Y. Mak, P. Laurino, P. H. Seeberger, Beilstein J. Org. Chem. 2009, 5, No. 19; (d) T. Tsubogo, T. Ishiwata, S. Kobayashi, Angew. Chem. Int. Ed. 2013, 52, 6590; (e) D. Zhao, K. Ding, ACS Catal. 2013, 3, 928; (f) A. Puglisi, M. Benaglia, V. Chiroli, Green Chem. 2013, 15, 1790; g) C. Rodríguez-Escrich and M. A. Pericàs, Eur. J. Org. Chem. 2015, 1173.

4 (a) B. List, Chem. Rev. 2007, 107, 5413; (b) D. W. C. MacMillan, Nature 2008, 455, 304; (c) P. Melchiorre, M. Marigo, A. Carlone, G. Bartoli, Angew. Chem. Int. Ed. 2008, 47, 6138; (d) A. Dondoni, A. Massi, Angew. Chem. Int. Ed. 2008, 47, 4638; (e) S. Bertelsen, K. A. Jørgensen, Chem. Soc. Rev. 2009, 38, 2178.

5 For early examples with PEG-supported proline, see: (a) M. Benaglia, G. Celentano, F. Cozzi, Adv. Synth. Catal. 2001, 343, 171; (b) M. Benaglia, M. Cinquini, F. Cozzi, A. Puglisi, G. Celentano, Adv. Synth. Catal. 2002, 344, 533. For reviews on immobilized organocatalysts, see: (c) M. Benaglia, A. Puglisi, F. Cozzi, Chem. Rev. 2003, 103, 3401; (d) M. Gruttadauria, F. Giacalone, R. Noto, Chem. Soc. Rev. 2008, 37, 1666; (e) T. E. Kristensen, T. Hansen, Eur. J. Org. Chem. 2010, 3179.

6 For examples, see: (a) F. Calderón, R. Fernández, F. Sánchez, A. Fernández-Mayoralas, Adv. Synth. Catal. 2005, 347, 1395; (b) A. Corma, H. Garcia, Adv. Synth. Catal. 2006, 348, 1391; (c) V. Polshettiwar, B. Baruwati, R. S. Varma, Chem. Commun. 2009, 1837; (d) P. Riente, C. Mendoza, M. A. Pericàs, J. Mater. Chem. A 2011, 21, 7350; (e) A. Monge-Marcet, X. Cattoën, D. A. Alonso, C. Nájera, M. W. C. Man, R. Pleixats, Green Chem. 2012, 14, 1601; (f) P. Riente, J. Yadav, M. A. Pericàs, Org. Lett. 2012, 14, 3668; (g) Z. Yacob, A. Nan, J. Liebscher, Adv. Synth. Catal. 2012, 354, 3259; (h) P. García-García, A. Zagdoun, C. Copéret, A. Lesage, U. Díaz, A. Corma, Chem. Sci. 2013, 4, 2006.

7 (a) D. Font, C. Jimeno, M. A. Pericàs, Org. Lett. 2006, 8, 4653; (b) E. Alza, X. C. Cambeiro, C. Jimeno, M. A. Pericàs, Org. Lett. 2007, 9, 3717; (c) D. Font, S. Sayalero, A. Bastero, C. Jimeno, M. A. Pericàs,
Org. Lett. 2008, 10, 337; (d) A. V. Malkov, M. Figlus, P. Kočovský, J. Org. Chem. 2008, 73, 3985; (e) E. Alza, M. A. Pericàs, Adv. Synth. Catal. 2009, 351, 3051; (f) S. H. Youk, S. H. Oh, H. S. Rho, J. E. Lee, J. W. Lee, C. E. Song, Chem. Commun. 2009, 2220; (g) E. Alza, S. Sayalero, P. Kasaplar, D. Almaşi, M. A. Pericàs, Chem. Eur. J. 2011, 17, 11585; (h) A. Puglisi, M. Benaglia, R. Annunziata, J. S. Siegel, ChemCatChem 2012, 4, 972.

8 (a) E. Alza, C. Rodríguez-Escrich, S. Sayalero, A. Bastero, M. A. Pericàs, Chem. Eur. J. 2009, 15, 10167; (b) E. Alza, S. Sayalero, X. C. Cambeiro, R. Martín-Rapún, P. O. Miranda, M. A. Pericàs, Synlett 2011, 464; (c) X. C. Cambeiro, R. Martín-Rapún, P. O. Miranda, S. Sayalero, E. Alza, P. Llanes, M. A. Pericàs, Beilstein J. Org. Chem. 2011, 7, 1486; (d) S. B. Ötvös, I. M. Mándity, F. Fülöp, ChemSusChem 2012, 5, 266; (e) C. Ayats, A. H. Henseler, M. A. Pericàs, ChemSusChem 2012, 5, 320; (f) X. Fan, S. Sayalero, M. A. Pericàs, Adv. Synth. Catal. 2012, 354, 2971; (g) O. Bortolini, L. Caciolli, A. Cavazzini, V. Costa, R. Greco, A. Massi, L. Pasti, Green Chem. 2012, 14, 992; (h) Y. Arakawa, H. Wennemers, ChemSusChem 2013, 6, 242; (i) V. Chiroli, M. Benaglia, A. Puglisi, R. Porta, R. P. Jumde, A. Mandoli, Green Chem. 2014, 16, 2798; (j) L. Osorio-Planes, C. Rodríguez-Escrich, M. A. Pericàs, Chem. Eur. J. 2014, 20, 2367.

9. For a discussion of the TON and TOF concepts in catalytic cycles, see: S. Kozuch and J. M. L. Martin, ACS Catal. 2012, 2, 2787.

10. O. V. Maltsev, A. O. Chizhov and S. G. Zlotin Chem. Eur. J. 2011, 17, 6109 .

11 For reviews on homogeneous H-bonding catalysis, see: (a) P. R. Schreiner, Chem. Soc. Rev. 2003, 32, 289; (b) X. Yu, W. Wang, Chem. Asian J. 2008, 3, 516; (c) Ł. Albrecht, H. Jiang, K. A. Jørgensen, Chem. Eur. J. 2014, 20, 358.

12 (a) P. Kasaplar, P. Riente, C. Hartmann, M. A. Pericàs, Adv. Synth. Catal. 2012, 354, 2905; (b) P. Kasaplar, C. Rodríguez-Escrich, M. A. Pericàs, Org. Lett. 2013, 15, 3498.

13 (a) G. Kardos, T. Soós, Eur. J. Org. Chem. 2013, 4490; (b) X. Xu, T. Cheng, X. Liu, J. Xu, R. Jin, G. Liu, ACS Catal. 2014, 4, 2137.

14 (a) a) A. Bøgevig, K. Juhl, N. Kumaragurubaran, W. Zhuang, K. A. Jørgensen, Angew. Chem. Int. Ed. 2002, 41, 1790; (b) B. List, J. Am. Chem. Soc. 2002, 124, 5656.

15 J. E. Hein, A. Armstrong, D. G. Blackmond, Org. Lett. 2011, 13, 4300.

16 X. Xu, T. Yabuta, P. Yuan, Y. Takemoto, Y. Synlett 2006, 137.

17 T. Inokuma, M. Furukawa, T. Uno, Y. Suzuki, K. Yoshida, Y. Yano, K. Matsuzaki, Y. Takemoto, Chem. Eur. J. 2011, 17, 10470.

18 S. H. Jung, D. Y. Kim, Tetrahedron Lett. 2008, 49, 5527.

19 H. Konishi, T. Y. Lam, J. P. Malerich, V. H. Rawal, Org. Lett. 2010, 12, 2028.

20 For a review on the use of click chemistry to immobilize catalysts, see: A. E. Fernandes, A. M. Jonas, O. Riant, Tetrahedron 2014, 70, 1709.

21 (a) S. Özçubukçu, E. Ozkal, C. Jimeno, M. A. Pericàs, Org. Lett. 2009, 11, 4680; (b) E. Ozkal, S. Özçubukçu, C. Jimeno, M. A. Pericàs, Catal. Sci. Technol. 2012, 2, 195; (c) E. Ozkal, P. Llanes, F. Bravo, A. Ferrali, M. A. Pericàs, Adv. Synth. Catal. 2014, 356, 857.

22 S. M. Kim, J. H. Lee, D. Y. Kim, Synlett 2008, 17, 2659.

23 For a proposed activation mechanism for thiourea organocatalysts, see: (a) T. Okino, Y. Hoashi, T. Furukawa, X. Xu, Y. Takemoto, J. 
Am. Chem. Soc. 2005, 127, 119; for a theoretical study: (b) A. Hamza, G. Schubert, T. Soós, I. Pápai, J. Am. Chem. Soc. 2006, 128, 13151.

24 For some examples, see: (a) S. Orlandi, A. Mandoli, D. Pini, P. Salvadori, Angew. Chem., Int. Ed. 2001, 40, 2519; (b) A. Doherty, P. Goodrich, C. Hardacre, V. Pàrvulescu, C. Paun, Adv. Synth. Catal. 2008, 350, 295; (c) J. Yadav, G. R. Stanton, X. Fan, J. R. Robinson, E. J. Schelter, P. J. Walsh, M. A. Pericàs, Chem. Eur. J. 2014, 20, 7122 .

25 Examples of PS H-bonding organocatalysts: (a) M. S. Sigman, E. N. Jacobsen, J. Am. Chem. Soc. 1998, 120, 4901; (b) M. S. Sigman, P. Vachal, E. N. Jacobsen, Angew. Chem., Int. Ed. 2000, 39, 1279; (c) H. Miyabe, S. Tuchida, M. Yamauchi, Y. Takemoto, Synthesis 2006, 19, 3295; (d) Y. Chuan, G. Chen, Y. Peng, Tetrahedron Lett. 2009, 50, 3054; (e) L. Tuchman-Shukron, M. Portnoy, Adv. Synth. Catal. 2009, 351, 541; (f) J. Li, G. Yang, Y. Qin, X. Yang, Y. Cui, Tetrahedron: Asymmetry 2011, 22, 613; (g) S. Fotaras, C. G. Kokotos, G. Kokotos, G. Org. Biomol. Chem. 2012, 10, 5613; (h) K. A. Fredriksen, T. E. Kristensen, T. Hansen, Beilstein J. Org. Chem. 2012, 8, 1126; (i) L. Tuchman-Shukron, S. J. Miller, M. Portnoy, Chem. Eur. J. 2012, 18, 2290.

26 H-bonding catalysts on Si-based supports: (a) A. Puglisi, M. Benaglia, E. Massolo, G. Celentano, Recycl. Catal. 2012, 1, 1; (b) P. Yu, J. He, C. Guo, Chem. Commun. 2008, 2355.

27 Due to restricted rotation around the carbamate $\mathrm{C}-\mathrm{N}$ bonds, the hydrazination products exist as mixtures of rotamers at room temperature. As a result, complex NMR spectra with broad and/or multiple signals are obtained. For this complexity, listing of chemical shifts is omitted. Actual spectra matching those reproduced in the literature $^{28,29}$ are reproduced in the Supporting Information.

28 M. Terada, M. Nakano, H. Ube, J. Am. Chem. Soc. 2006, 128, 16044.

29 H. Konishi, T. Y. Lam, J. P. Malerich, V. H. Rawal, Org. Lett. 2010, $12,2028$. 